\begin{tabular}{c} 
Volume and Issues Obtainable at Center for Sustainability Research and Consultancy \\
Journal of Business and Social Review in Emerging Economies \\
ISSN: 2519-089X (E): 2519-0326 \\
Volume 5: Issue 1 June 2019 \\
CSRட \\
Journal homepage: $\underline{\text { www.publishing.globalcsrc.org/jbsee }}$ \\
\hline
\end{tabular}

\title{
Drivers and Barriers of Sustainability Practices in Emerging and Developing Economies
}

\author{
${ }^{1}$ Zeeshan Mahmood, ${ }^{2}$ Waris Ali, ${ }^{3}$ Javed Iqbal, ${ }^{4}$ Sadaf Fatima \\ ${ }^{1}$ Department of Commerce, Bahauddin Zakariya University, Multan, Pakistan. zeeshanmahmood@bzu.edu.pk \\ ${ }^{2}$ Department of Management Sciences, University of Sahiwal, Sahiwal Pakistan. waris.ali@bzu.edu.pk \\ ${ }^{3}$ Institute of Management Sciences, Bahauddin Zakariya University, Multan, Pakistan. javediqbal@bzu.edu.pk \\ ${ }^{3}$ Department of Commerce, Bahauddin Zakariya University, Multan, Pakistan. sadaf.fatima.sahu @ gmail.com
}

\begin{tabular}{l}
\hline ARTICLE DETAILS \\
\hline History \\
Revised format: May 2019 \\
Available Online: June 2019 \\
\\
\hline Keywords \\
Sustainability practices, \\
SMEs, \\
Institutional theory, \\
Emerging Economies, \\
Pakistan.
\end{tabular}

\section{JEL Classification:}

Q56, B52

\begin{abstract}
This paper examines the drivers and barriers to adopt sustainability practices in Pakistani SMEs. Corporate sustainability has become important issue during the last few decades. Existing literature focus on large companies and thereby paid limited attention to SMEs. There is an increased understanding that SMEs should focus on sustainability practices to remain competitive. There is limited research that capture the extent of adoption of sustainability practices as well as its drivers and barriers. This paper fills the gap and uses institutional theory to explain the drivers and barriers of sustainability practices in SMEs of Pakistan. This qualitative research was conducted in Multan, Pakistan where interviewees from the managers of eight SMEs in the manufacturing sector were conducted. In addition to this questionnaire was sent to SMEs in order to capture the extent of the adoption of sustainability practices. The research findings show certain drivers: commitment by top management, competitor pressure, stakeholders' pressure and barriers: lack of resources, lack of training and education and lack of awareness for the adoption of sustainability practices. This paper contributes to the sustainability literature in emerging and developing countries. Through an increased awareness of drivers and barriers, policy makers and practitioners may take necessary steps to improve sustainability practices in SMEs
\end{abstract}

(C) 2019 Center for Sustainability Research and Consultancy Pakistan under a Creative Commons Attribution-NonCommercial-ShareAlike 4.0

Corresponding author's email address: zeeshanmahmood@bzu.edu.pk

Recommended citation: Mahmood, Z., Ali, W., Iqbal, J. and Fatima, S. (2019). Drivers and Barriers of Sustainability Practices in Emerging and Developing Economies. Journal of Business and Social Review in Emerging Economies, 5 (1) 213-222

DOI: DOI 10.26710/jbsee.v5i1.683

\section{Introduction}

Pressure on Companies to adopt sustainability practices has been increased due to the globalization. Various supranational institutions, governmental as well as non-governmental organizations and professional associations are promoting the agenda for sustainable development. Prior to the year 1980, sustainable development was part of the environmental lexicon, especially in the third world development context. The concept of sustainable development gained momentum when the World Commission on Environment and Development (WCED) defined the term as 'development that meet the needs of the present without compromising the ability of future generation to meet their own need' (Brundtland, 1987, p. 43). "Sustainability" is a term that has also many definitions. Many authors use this term by different names in their papers like energy efficiency, green practices, environmental management (Hillary, 2004; Trianni, Cagno, Thollander, \& Backlund, 2013). The term sustainability has emerged 
over time from the "triple bottom-line" consideration that includes social, economic and environmental responsibility (Lu et al., 2015).

Corporate behavior for sustainable development has acquired new relevance recently. The increasing interest in sustainability is because of the increasing occurrence and growing awareness of the socioeconomic and environmental issues. Previous literature shows the issues facing by the organizations due to the environment. There is a propensity to legitimize firms that act in a socio-responsible manner toward environmental impact (Vincenza Ciasullo \& Troisi, 2013). Climate change has become one of the greatest challenges for mankind today. Our ecosystem is deteriorating due to the increased deforestation, consumption of non-renewable resources and global warming. With the increased problems related to the environment like global warming, air pollution, water pollution, waste problems and land degradation, most of the firms have moved towards engaging and practicing environmentally friendly practices (Leonidou, Katsikeas, Fotiadis, \& Christodoulides, 2013). These challenges appeared to be the great and most important challenges, not only for humanity but also, for the sustainability of the business (Kim, Kim, \& Qian, 2018). Thus, now it has become compulsory for the firms to take up the matter seriously, by developing new strategies, in order to survive in this new business environment (Guenther \& Hoppe, 2014)

Business organizations are an important player for sustainable development. The activities of the business may contribute both positively and negatively to sustainable development (Gray \& Milne, 2002; Herzig \& Schaltegger, 2006). In recent years, the demands for business behaviors that are consistent with sustainability are increasing (Milne, Tregidga, \& Walton, 2009). Therefore, the concept of corporate sustainability is gaining prominence in the agenda of governmental and non-governmental organizations (Christofi, Christofi, \& Sisaye, 2012; Montiel \& Delgado-Ceballos, 2014). The concept of corporate sustainability is based on the fundamental belief that business, through sustainable performance, can deal with sustainable development. this context, corporate sustainability performance, can be considered as the degree to which an organization incorporates global sustainable performance, can be considered as the degree to which an organization incorporates global sustainable development responsibilities into its business strategy and operations (Morioka \& de Carvalho, 2016). Over the years, several practices (e.g. sustainability accounting, sustainability reporting, sustainability balanced scorecard) has been develops to incorporate the dimensions of corporate sustainability so that companies can contribute to sustainable development (Lourenço \& Branco, 2013).

Firms are under ever increasing pressure by investors, policy makers, stakeholders and shareholders to adopt sustainability practices and to consider sustainability performance more seriously (Morioka \& de Carvalho, 2016). Existing research on sustainability has focused on pressures, challenges and opportunities to adopt sustainability practices in big organizations and moreover due to these pressures and opportunities the firms are getting involved the sustainability practices. Mostly big corporations have taken step to adopt sustainable practices, but small and medium enterprises are less aware, However the existing research on sustainability lacks the issues and opportunities of the sustainability practices in the small and medium enterprises.

\section{Sustainability Practices in Small and Medium Enterprises}

Sustainability incorporates social, environmental and economic impacts on business. It is important for the economic growth and employment that the sustainable business practices should be maintained. Sustainable practices ensure the social progress, recognition the needs of everyone and they preserve the natural resources in future. Previous studies have focused on analysis of existing sustainable practices in different countries. For example, (Retamal, 2017) identified some sustainable practices in their study that include: use of durable quality goods, repair, recycling, minimize transport of goods, minimum disposable packaging, reduce private vehicle kilometer travelled. Delai and Takahashi (2013) also added some practices to the literature that include (1) environmental; air (global warming, human health effect, ozone depletion), Water (consumption, acid), land (land use, waste production), energy (consumption and resources), materials (dissatisfaction of consumption and consumption), bio-avid and products and services (product recycling and environmentally friendly products (2) Social warehouse and decent work (education, training and development), corporate citizenship, customer relationship management, suppliers and partners and public sector ( taxes and subsidies). Similarly, Font, Garay, and Jones (2016) explains some sustainability practices in their research that include (1) environmental: to use environmental friendly products, recycling the waste, energy and water saving activities (2) social: encourage people to apply for jobs, in your employment practices promote gender equality, facilities are adopted for disables persons (3) economic: encourage customers to use local products, wherever possible choose local staff, salaries of 
the staff are above industry average. After reviewing these studies and other literature (see. e.g., De Silva \& Forbes, 2016; Delai \& Takahashi, 2013; Retamal, 2017; Scur \& Barbosa, 2017) we derived a list of practices that are commonly referred as sustainability practices. These practices include: waste management, recycling, energy saving, water saving, customer satisfaction, packaging, total quality management, employee education and training and sustainability reporting. This study is using these practices for research.

Due to many problems facing SMEs, many developed countries have set rules that are specific to small and medium enterprises. These regulations protect small and medium enterprises while regulating their environmental impact. Many studies show that there is lack of such regulations in developing countries. But mostly developed countries have set regulation regarding sustainability practices. Like, in the United States, Regulatory Flexible Act (RFA) and Small Business Regulatory Implementation Act (SBREFA) wants to provide SMEs with clear and guidance on the environmental management regulatory. Although an individual SME, because of small size, may have a relatively low impact on the environment, their overall impact is huge on account of large size of the SME sector (Brammer, Hoejmose, \& Marchant, 2012). SMEs are providing 90\% of the worldwide business and $70 \%$ pollution is generated by SMEs, yet the literature shows the mainly focus of sustainability on large organizations, often multinational companies.

The economy of Pakistan is heavily dependent on SMEs. Ninety nine percent of Pakistani business consists of SMEs which is contributing to $40 \%$ of Pakistani GDP, $70 \%$ of Pakistan's on agricultural employment, $25 \%$ of Pakistan's export earnings and $35 \%$ of the value-added manufacturing industry. In any economy, SMEs plays crucial role. They provide jobs and contributes in the economy in different ways. Pakistan is a country with larger population, a country having noticeable debt and export/import imbalances. Given the importance of SMEs in the economy on national and international level and its impact on social and environmental issues it was surprising that SMEs relatively marginalized in the discussion on sustainability and relatively ignored in academic research.

The concept of sustainability in Pakistan is quite new. There is imperative need to understand the sustainability/environmental and social issues for the Pakistani business community. The organizations are considered as being innovative that are adopting sustainable practices. The business community of Pakistan needs to adopt these sustainable business practices not only to respond the challenges of the sustainable development of Pakistan, but also to comply with the competitor and regulatory pressures. In this perspective, this research aims to identify some sustainable business practices adopting by different country's organizations. ACCA Pakistan has conducted a research on sustainability practices. The research shows twelve sustainability practices that is taken in this research. The practices are "Energy saving, water saving, reducing in fertilizer use, concern for bio diversity, water purification, compliance with product and waste disposal regulations, employee education and training, workforce diversity, workforce health care provision, community investment/local philanthropy, conformity with recognized environmental management standards, e.g. ISO14401, sustainability reporting".

Existing research has identified many drivers for the adoption of sustainable business practices. According to bin Ibrahim and binti Jaafar (2016) key drivers include: customer pressure, regulatory pressure, government support and uncertainty of environment.. Some other factors identified by Scur and Barbosa (2017) include environmental regulations, stakeholder and customer pressure, financial benefits, competitors, market trends, company image, environmental conservation, supply chain requirements, green innovation, internal motivations and employee demand. Yusof, Abidin, Zailani, Govindan, and Iranmanesh (2016) has identifies internal and external environmental drivers to implement sustainable practices. Internal drivers include organizational support and quality of human resources and external drivers includes customer pressure, regulatory pressure and government support.

Numerous studies also highlighted many barriers experienced by owners-managers regarding environment and sustainability practices (Lawrence, Collins, Pavlovich, \& Arunachalam, 2006). These barriers include external factors such as lack of awareness, lack of knowledge and skill, the lack of consumer demand and supply chain pressure for environmental reform. These barriers also include internal barriers, such as owner-managers' perception that their firms' impact is insignificant (Lawrence et al., 2006). (Ghazilla et al., 2015) identify some barriers to implement sustainable practices that are organizational, environmental knowledge, business environment, societal influence, technology, regulation/government, financial and supplier).The previous research has suggested that "the lack of resources" is a major obstacle Environmental measures, including financial resources, knowledge and loss in time between SMEs (Sweeney, 2007). High investment costs and lack of 
financial resources, doubtful payback about green investment, lack of human resources in green initiatives, lack of ICT skills for managing green initiatives, lack of environmental customer awareness, lack of financial incentives and lack of well-defined regulations framework. These are some barriers pointed out by (Evangelista, 2014).

\section{Theoretical Framework:}

This study used institutional theory to explain the drivers of sustainability practices. According to a great number of researchers (for example Mohanty \& Prakash, 2014; Zhu, Sarkis, \& Lai, 2007) institutional pressure is one of the most important factors that have encouraged companies to implement sustainability practices. According to institutional theory (Scott, 2008), adoption of sustainability practices may be result of three different types of pressure; coercive pressure (the pressure from the regulatory bodies and government), Mimetic pressure (The pressure from competitors and rivals), and the normative pressure (that comes from market and public).

Institutional Theory has been used extensively in studies exploring environmental management (e.g. Bansal, 2005; Hoffman, 1999). Coercive pressure includes the pressure from stakeholders like customers, regulations and competitors. According to Large and Thomsen (2011) the customers and stakeholders are responsible for the environmental performance of the organizations. In this context, besides companies, partners like governments, consumers and environmental organizations have also played a role in increasing the of sustainability practices. The normative pillar focuses on values and norms (Scott, 2008). The main role in the field builds social expectations, which include what is necessary for an organization and how things should be done. These expectations become external pressure for an organization in which the organization adopts organizational methods with great motivation to respect social responsibilities (Greenwood, Oliver, Lawrence, \& Meyer, 2017). Manufacturers can be motivated through normative driver to start their sustainable purchasing effort Normative pressures are very important for organizations to implement sustainable practices and it can come from consumers and sustainable organizations can (Barber, 2007). Mimetic drivers can promote manufacturers to learn from those pioneer companies. Mimetic drivers motivate companies to emulate the practices of successful competitors in the industry. Manufacturers have gained the opportunities to learn, how to compete in the industry, from domestic and foreign competitor (Gollagher et al., 2010).

\section{Research methodology}

This research adopts qualitative methodology as it is best suited to capture the perceptions of respondents about various issues (for example benefit, drivers and barriers). It allows researcher to be involved in the research process. There is absence of the qualitative methods in the field of sustainability practices in SMEs, especially in the context of Pakistan. This method is different in the context of data collection, interaction with different participants, analyzing data and findings. Qualitative method is important because it deals with the values and ideologies that help the deepen research. This study contains three research questions. The first question relate to the extent SMEs are adopting sustainability practices. To answer this, question a questionnaire was developed and distributed to managers of different SMEs. A total of 200 questionnaires were filled and duly received by us. The second and third questions relate to the drivers and barriers of sustainability practices. To answers these questions semi-structured interviews were conducted with managers of SMEs based in Multan. The 8 Small and Medium Enterprises investigated are in the Multan region. As it is impossible both financially and physically, to survey all SMEs in all categories i.e. manufacturing, trading, services and textile. So, this study chooses the textile sector for interviews.

\section{Results}

\subsection{Sustainability practices have been adopted in Pakistani SMEs}

The extent of use was analyzed by filling the questionnaires. Table below shows the results of the questionnaires.

Table 5: Extent of use of sustainability practices

\begin{tabular}{|l|l|l|l|l|l|l|}
\hline Practices & $\%$ & \multicolumn{5}{|l|}{ Extent of use } \\
& & None & Rarely & Occasionally & Frequently & $\begin{array}{l}\text { Very } \\
\text { Frequently }\end{array}$ \\
\hline $\begin{array}{l}1-\text { Waste } \\
\text { Management }\end{array}$ & $85 \%$ & $15 \%$ & $5 \%$ & $6 \%$ & $70 \%$ & $4 \%$ \\
\hline
\end{tabular}




\begin{tabular}{|l|l|l|l|l|l|l|}
\hline 2-water saving & $60 \%$ & $10 \%$ & $8 \%$ & $32 \%$ & $10 \%$ & $0 \%$ \\
\hline 3-Energy saving & $60 \%$ & $40 \%$ & $16 \%$ & $30 \%$ & $14 \%$ & $0 \%$ \\
\hline $\begin{array}{l}\text { 4-Recycling } \\
\text { process }\end{array}$ & $58 \%$ & $52 \%$ & $38 \%$ & $11 \%$ & $9 \%$ & $0 \%$ \\
\hline $\begin{array}{l}\text { 5-Customer } \\
\text { satisfaction }\end{array}$ & $75 \%$ & $5 \%$ & $0 \%$ & $6 \%$ & $53 \%$ & $11 \%$ \\
\hline $\begin{array}{l}\text { 6-Packaging } \\
\text { Management }\end{array}$ & $34 \%$ & $66 \%$ & $23 \%$ & $11 \%$ & $0 \%$ & $0 \%$ \\
\hline $\begin{array}{l}\text { 7-Total quality } \\
\text { management }\end{array}$ & $74 \%$ & $1 \%$ & $1 \%$ & $20 \%$ & $30 \%$ & $22 \%$ \\
\hline $\begin{array}{l}\text { 8-Employee } \\
\text { education and } \\
\text { training }\end{array}$ & $75 \%$ & $5 \%$ & $5 \%$ & $10 \%$ & $53 \%$ & $2 \%$ \\
\hline $\begin{array}{l}\text { 9- Sustainability } \\
\text { reporting }\end{array}$ & $20 \%$ & $80 \%$ & $15 \%$ & $5 \%$ & $0 \%$ & $0 \%$ \\
\hline
\end{tabular}

\subsection{Barriers to adopt sustainability practices}

\subsubsection{Lack of resources}

We found that many companies do not invest in sustainability practices due to the lack of resources. In an interview the respondent says,

"Limited access to capital prevents us to adopt sustainability practices. Although we are trying to adopt these practices but still, we are not practicing. Because our organization is small enterprise, we don't have enough budget to adopt sustainability practices" (Intervieweel)

Resources is not big issue for big corporations, but for small and medium enterprises lack of resources is main issue. Many SMEs do not have enough finances to implement sustainable practices. Like the argument of Apeaning and Thollander (2013) that the lack of capital is the main barrier for SMEs to adopt sustainability practices, that prohibits the organizations to adopt sustainability practices. another interviewee says,

"If we adopt such practices, this require finance to initiate. And we have limited resources and finance to carry on our day to day operations. We mainly work on our goal that is making production. But we use some measures we feel that they are compulsory for our organization. Because our organization is textile, so we follow some measures like labor safety laws" (interviewee 4)

Thollander, Danestig, and Rohdin (2007) identified that SMEs tend to prioritize other capital investment, but they ignore the adoption of sustainability practices. Consistent with their view, one of the respondents said that as the have limited resources so they priorities to invest in other projects for the sake of profit.

"As every organization's purpose is to make profit. Our organization is small sized and have limited resources. So, our top management priorities to invest in other capital investment rather to invest sustainability practices. It is obvious that adoption of sustainability practices takes capital and we (SME) don't have enough finance to adopt these practices" (Interviewee 6)

\subsubsection{Lack of awareness}

Lack of awareness has been identified as another main barrier for the adoption of sustainability practices. Besides this, if people are aware than they resist to change, this is also the barrier while implementing sustainable practices. One of the respondents said, 
"The personnel's in our organizations may resist to change if we adopt these sustainability practices. Moreover, they may also not have environmental values, therefore they give a lower priority to sustainability practices" (Interviewee 6)

Most of the SMEs have a problem that their managers were unaware about sustainability practices. The lack of expertise and understanding of strategies to address environmental issues is the second barrier. Many SMEs not having expertise have trouble to adopt sustainable practices (Simpson, Taylor, \& Barker, 2004). Consistent with the views of the authors one of the interviewees says,

"Management is unaware about the long-term benefits of sustainability practices. This is barrier for our organization that management is unaware of the benefits of the sustainability practices. Moreover, our organization does not have expertise to make strategies for implementing these practices, so this is the main barrier for us (SME)" (Interviewee 1)

However, not all managers agree with this point that lack of awareness is the main issue. For example, one of the interviewees explain in these words.

"I am not agreeing that the managers are unaware about sustainability practices. Now days every organization knows about the perceived benefits of these practices. Many organizations are moving towards these practices. As well as our organization is concerned, as a manager I am aware about sustainability practices, but our upper management is not making any rules to adopt sustainability practices" (Interviewee 4)

\subsubsection{Lack of staff Training and skill}

Most of the SMEs are facing the problem of staff training and lack of skills. When we take the interviews some of the SMEs showed that they have old staff. They have no adequate skills that are necessary to use these sustainability practices. So, keeping in mind the perspective of the previous studies we ask from one of the respondents about this fact he says,

"Training is the best thing whenever any organization want to change something. Because we cannot replace whole the staff, so the best way is to organize the trainings. But there are no training programmers held in our organizations, so many of the members of the organization do not have enough capabilities to adopt sustainability practices" (Interviewee 1)

Level of knowledge and experience of the managers and other staff is very important for adopting sustainability practices. Similarly, awareness to seek knowledge about change is also important. For this purpose, teamwork is leading factor. One of the respondents talks about this factor, he says,

"Nothing is impossible to learn. We know adopting sustainability practices are beneficial for our (SME) organization. But according to me there is lack of coordination and lack of teamwork too that leads to problem of learning about these practices. If the management emphasis on teamwork than may $b$ there is no need for special training programme" (Interviewee 6)

\subsection{Drivers to adopt Sustainability practices \\ 5.3.1 Stakeholders pressure}

Bianchi and Noci (1998) suggest that environmental management in SMEs stems from one of two channels; either the attitudes of managers-owners or stakeholder pressure and interaction. One of the respondents says,

"We are using CSR approach and it is highly appreciated to achieve goals with social responsibility. We are using sustainability practices because of our stakeholder's demand. Obviously, stakeholders who invests in our organization, they pressurize us to adopt sustainability practices" (Interviewee 3)

Sustainability is related in the context with responsibility and is defined by the owner values. Most of the stakeholders have believe that the organization should adopt those policies and acts that will show the norms and values of the organization. Many stakeholders pressurize their enterprises to adopt sustainability practices because in this way they feel honorable because these practices show that they care about the lives of the people and their 
organization have values. One of the interviewees says,

"Yes, we are using sustainability practices. The main reason why we are adopting these practices is the pressure from our stakeholders. They believe that this shows our norms and values and our care towards people. Personally, I also believe that by using sustainability practices our image will increase, in the sense that we (SMEs) are working on the base of values." (Interviewee 7)

Consistent with the results of these authors one of the respondents give the statement,

"I must say that due to the pressure of our stakeholders we are adopting sustainability practices. According to me this is not necessary that if we adopt sustainability practices, our financial performance will increase. But our stakeholders believe that the financial performance will increase if we adopt sustainability practices" (Interviewee1)

\subsubsection{Competitors pressure}

Majority of SMEs have competitors' pressure to adopt sustainability practices. One of the respondents say

"Yes, we are adopting sustainability practices as it could provide a competitive advantage. We (SME) have a strategy "have a keen eye on your competitors" to compete our rivals. So, we have to adopt sustainability practices because our competitors are moving toward these practices" (Interviewee 1)

While taking interview from one of the interviewees, he revealed the fact that was quite different from the others. According to him, their organization have enough financial resources to continue their operations and they are making very good profit, so he commented,

"Why you think there is always a competitive pressure behind adopting any strategies? We have our own system, our own strategies. We are doing our best and we are on the high ratio of profit. We don't see what our competitors are doing. We always work on our set strategies. We do what we must do. Although we are adopting sustainability practices but not because of our competitors, but because of our own set strategies" (Interviewee 3)

\subsubsection{Regulatory pressure}

Legislation appears to be one of the main drivers of sustainability practices amongst SMEs as reported by the following interviewee.

"We are facing regulatory pressure from government. We are adopting some of the sustainability practices by our own. But there are some practices which we have to adopt because of the regulatory pressure like it is compulsory for the textile enterprises to have 5\% open area" (Interviewee 2)

Environmental fitness is a compulsory factor the governments demand from organizations (Mohanty \& Prakash, 2014). According to Carbone and Moatti (2011) some current studies explore that for adopting sustainability practices, there are different standards, depending on the type of institutional pressure. Pakistani Government have also implemented many acts and regulations for environment protection. Similarly, when we interviewed one of the SMEs, they explain the fact that there are many regulations from

"We have regulatory pressure to adopt sustainability practices. According to me now it is trending to adopt sustainability practices due to many reasons, one of the important reasons is the rules and regulations imposed by the government to save the environment." (Interviewee 1)

The concept of sustainability is growing in Pakistan. With the growing concept of sustainability practices the regulations by government are also increased. Some organizations are adopting sustainability practices because they feel it necessary to save the environment, other are adopting because of the regulatory pressure by the government. There are many laws and regulations prepared by the government of Pakistan to save the environment. While interviewing, one of the respondents explore about the regulations they have to follow. In his words,

"Government have implemented some rules regarding environmental protection. It is mandatory for us to 
follow those rules. Labor safety laws and waste disposals are the rules that we are following by the pressure of the government." (Interviewee 5)

\subsection{Commitment by the top management:}

Management is the main thing for the achievement of the long-term goals. While taking interviews one of the respondents says,

"According to me, management has key role in the adoption of sustainability practices. Many organizations have strategies on the implementation of sustainability practices, but few are implementing, because their management is not serious in practicing. So, if the top management is committed, it can drive organizations to adopt such practices". (Interviewee 8)

Another respondent elaborates about the regulations set by the top management. Strict environmental regulations by the top management pushes the organizations to adopt the sustainability practices to reduce the cost and increase the efficiency. In his words,

"We (SME) are adopting sustainability practices because our top management has strict regulations to adopt these practices. As far as, I know the reason is not that the other firms are adopting so we should, rather by adopting sustainability practices, the cost can be reduced, and the overall firm's efficiency increased." (Interviewee 5)

\section{Conclusion:}

Our research confirms the presence of coercive, normative and mimetic pressures in the adoption of sustainability practices. According to our interviewees important drivers of sustainability practices are the regulatory pressure (Coercive), stakeholder's pressure (Normative), competitor's pressure (Mimetic) and commitment by top management. Our research also shows some barriers to adopt these practices that are lack of resources, lack of training and education, and lack of awareness. Consistent with the results of Vanalle, Ganga, Godinho Filho, and Lucato (2017), this research has concluded that competitive pressures and stakeholder pressures are one of the main driver for the adoption of sustainability practices. Stakeholders exert normative pressures on companies to implement ecofriendly environmental practices. Firms employ their resources to implement the sustainability practices to answer their stakeholders. The research findings show that SMEs adopts sustainability practices if there are regulatory pressure. This is the driver to adopt sustainability practices and called coercive driver. Regulatory pressures forces SMEs to adopt sustainability practices. This study confirms lack of resources, lack of training and lack of awareness as main barrier in the adoption of sustainability practices. Scarcity of these resources result in limited normative pressure which means that sustainability practices are mainly driven by coercive and normative pressures.

This research has some practical implications. First this research will help the policy makers by highlighting the barriers which are faced by SMEs in the implementation of sustainability practices. This study confirms the lack of normative pressures which is why the adoption of sustainability practices is limited. Policy makers can make sustainability education part of the curriculum at different levels. In the absence of normative pressures, policy makers may think of taking the regulatory route to enforce the adoption of sustainability practices. There is also a need to change the mindset of the managerial staff of SMEs that sustainability practices bring benefits for the company. This research may be a beginning point for further investigation of sustainability practices among SMEs in Pakistan and promote Pakistani researchers' interest to use SMEs sector as a population. It is expected that the Pakistani government will give more attention towards sustainability practices in SMEs and improve existing training programmes on the adoption of sustainability practices.

\section{References}

Apeaning, R. W., \& Thollander, P. (2013). Barriers to and driving forces for industrial energy efficiency improvements in African industries-a case study of Ghana's largest industrial area. Journal of Cleaner Production, 53, 204-213.

Bansal, P. (2005). Evolving sustainably: A longitudinal study of corporate sustainable development. Strategic Management Journal, 26(3), 197-218.

Bianchi, R., \& Noci, G. (1998). " Greening" SMEs' Competitiveness. Small Business Economics, 11(3), $269-281$.

bin Ibrahim, I., \& binti Jaafar, H. S. (2016). Factors of environment management practices adoptions. Procedia- 
Social and Behavioral Sciences, 224, 353-359.

Brammer, S., Hoejmose, S., \& Marchant, K. (2012). Environmental management in SME s in the UK: Practices, pressures and perceived benefits. Business strategy and the environment, 21(7), 423-434.

Brundtland, G. H. (1987). Report of the World Commission on environment and development:" our common future.": United Nations.

Carbone, V., \& Moatti, V. (2011). Towards greener supply chains: an institutional perspective. International Journal of Logistics Research and Applications, 14(3), 179-197.

Christofi, A., Christofi, P., \& Sisaye, S. (2012). Corporate sustainability: historical development and reporting practices. Management Research Review, 35(2), 157-172.

De Silva, T.-A., \& Forbes, S. L. (2016). Sustainability in the New Zealand horticulture industry. Journal of Cleaner Production, 112, 2381-2391.

Delai, I., \& Takahashi, S. (2013). Corporate sustainability in emerging markets: insights from the practices reported by the Brazilian retailers. Journal of Cleaner Production, 47, 211-221.

Evangelista, P. (2014). Environmental sustainability practices in the transport and logistics service industry: An exploratory case study investigation. Research in Transportation Business \& Management, 12, 63-72.

Font, X., Garay, L., \& Jones, S. (2016). Sustainability motivations and practices in small tourism enterprises in European protected areas. Journal of Cleaner Production, 137, 1439-1448.

Ghazilla, R. A. R., Sakundarini, N., Abdul-Rashid, S. H., Ayub, N. S., Olugu, E. U., \& Musa, S. N. (2015). Drivers and barriers analysis for green manufacturing practices in Malaysian SMEs: a preliminary findings. Procedia Cirp, 26, 658-663.

Gollagher, M., Sarkis, J., Zhu, Q., Geng, Y., Fujita, T., \& Hashimoto, S. (2010). Green supply chain management in leading manufacturers. Management Research Review.

Gray, R., \& Milne, M. (2002). Sustainability reporting: who's kidding whom? Chartered Accountants Journal of New Zealand, 81(6), 66-70.

Greenwood, R., Oliver, C., Lawrence, T. B., \& Meyer, R. E. (2017). The Sage handbook of organizational institutionalism: Sage.

Guenther, E. M., \& Hoppe, H. (2014). Merging limited perspectives: A synopsis of measurement approaches and theories of the relationship between corporate environmental and financial performance. Journal of Industrial Ecology, 18(5), 689-707.

Herzig, C., \& Schaltegger, S. (2006). Corporate sustainability reporting. An overview. In Sustainability accounting and reporting (pp. 301-324): Springer.

Hillary, R. (2004). Environmental management systems and the smaller enterprise. Journal of Cleaner Production, 12(6), 561-569.

Hoffman, A. J. (1999). Institutional evolution and change: Environmentalism and the US chemical industry. Academy of Management journal, 42(4), 351-371.

Kim, K.-H., Kim, M., \& Qian, C. (2018). Effects of corporate social responsibility on corporate financial performance: A competitive-action perspective. Journal of management, 44(3), 1097-1118.

Large, R. O., \& Thomsen, C. G. (2011). Drivers of green supply management performance: Evidence from Germany. Journal of Purchasing and Supply Management, 17(3), 176-184.

Lawrence, S. R., Collins, E., Pavlovich, K., \& Arunachalam, M. (2006). Sustainability practices of SMEs: the case of NZ. Business strategy and the environment, 15(4), 242-257.

Leonidou, L. C., Katsikeas, C. S., Fotiadis, T. A., \& Christodoulides, P. (2013). Antecedents and consequences of an eco-friendly export marketing strategy: The moderating role of foreign public concern and competitive intensity. Journal of International Marketing, 21(3), 22-46.

Lourenço, I. C., \& Branco, M. C. (2013). Determinants of corporate sustainability performance in emerging markets: the Brazilian case. Journal of Cleaner Production, 57, 134-141.

Lu, Y., Wang, R., Zhang, Y., Su, H., Wang, P., Jenkins, A., . . . Squire, G. (2015). Ecosystem health towards sustainability. Ecosystem Health and Sustainability, 1(1), 1-15.

Milne, M. J., Tregidga, H., \& Walton, S. (2009). Words not actions! The ideological role of sustainable development reporting. Accounting, Auditing \& Accountability Journal, 22(8), 1211-1257.

Mohanty, R., \& Prakash, A. (2014). Green supply chain management practices in India: an empirical study. Production Planning \& Control, 25(16), 1322-1337.

Montiel, I., \& Delgado-Ceballos, J. (2014). Defining and measuring corporate sustainability: Are we there yet? Organization \& Environment, 27(2), 113-139.

Morioka, S. N., \& de Carvalho, M. M. (2016). A systematic literature review towards a conceptual framework for integrating sustainability performance into business. Journal of Cleaner Production, 136, 134-146. 
Retamal, M. (2017). Product-service systems in Southeast Asia: Business practices and factors influencing environmental sustainability. Journal of Cleaner Production, 143, 894-903.

Scott, W. R. (2008). Institutions and organizations: Ideas and interests: Sage.

Scur, G., \& Barbosa, M. E. (2017). Green supply chain management practices: Multiple case studies in the Brazilian home appliance industry. Journal of Cleaner Production, 141, 1293-1302.

Simpson, M., Taylor, N., \& Barker, K. (2004). Environmental responsibility in SMEs: does it deliver competitive advantage? Business strategy and the environment, 13(3), 156-171.

Sweeney, L. (2007). Corporate social responsibility in Ireland: barriers and opportunities experienced by SMEs when undertaking CSR. Corporate Governance: The International Journal of Business in Society, 7(4), 516-523.

Thollander, P., Danestig, M., \& Rohdin, P. (2007). Energy policies for increased industrial energy efficiency: Evaluation of a local energy programme for manufacturing SMEs. Energy policy, 35(11), 5774-5783.

Trianni, A., Cagno, E., Thollander, P., \& Backlund, S. (2013). Barriers to industrial energy efficiency in foundries: a European comparison. Journal of Cleaner Production, 40, 161-176.

Vanalle, R. M., Ganga, G. M. D., Godinho Filho, M., \& Lucato, W. C. (2017). Green supply chain management: An investigation of pressures, practices, and performance within the Brazilian automotive supply chain. Journal of Cleaner Production, 151, 250-259.

Vincenza Ciasullo, M., \& Troisi, O. (2013). Sustainable value creation in SMEs: A case study. The TQM Journal, 25(1), 44-61.

Yusof, N. A., Abidin, N. Z., Zailani, S. H. M., Govindan, K., \& Iranmanesh, M. (2016). Linking the environmental practice of construction firms and the environmental behaviour of practitioners in construction projects. Journal of Cleaner Production, 121, 64-71.

Zhu, Q., Sarkis, J., \& Lai, K.-h. (2007). Green supply chain management: pressures, practices and performance within the Chinese automobile industry. Journal of Cleaner Production, 15(11-12), 1041-1052. 